OPEN ACCESS

Edited by:

Lijie Guo,

Beijing General Research Institute of

Mining and Metallurgy, China

Reviewed by:

Ping Duan,

China University of Geosciences

Wuhan, China

Yanli Huang,

China University of Mining and

Technology, China

*Correspondence:

Guodong Cao

gdcao@xtu.edu.cn

Yihua Liang

20150631@git.edu.cn

Specialty section:

This article was submitted to

Structural Materials,

a section of the journal

Frontiers in Materials

Received: 05 June 2021

Accepted: 11 October 2021

Published: 25 October 2021

Citation:

Deng D, Cao G and Liang Y (2021)

Filling Treatment of Surface

Subsidence Resulted From

Underground Mining in a High-

Altitude Mine.

Front. Mater. 8:720915.

doi: 10.3389/fmats.2021.720915

\section{Filling Treatment of Surface Subsidence Resulted From Underground Mining in a High-Altitude Mine}

\author{
Daiqiang Deng ${ }^{1,2}$, Guodong Cao ${ }^{1 *}$ and Yihua Liang ${ }^{3 *}$ \\ ${ }^{1}$ College of Civil Engineering and Mechanics, Xiangtan University, Xiangtan, China, ${ }^{2}$ College of Mining Engineering, Guizhou \\ Institute of Technology, Guiyang, China, ${ }^{3}$ Guizhou Industrial Development Research Center, Guizhou Institute of Technology, \\ Guiyang, China
}

In the process of filling the goaf of Huashugou copper mine, the filling aggregate was the mine's self-produced copper flotation tailings. The physical and chemical property tests showed that the tailings were relatively fine, and the cumulative contents of the $7.5,15,80$, and $90 \mu \mathrm{m}$ particles were 56.99, 79.46, 99.88, and 100\%, respectively. PSA42.5 Portland slag cement was selected as the cementing material for the tests. The amount of finely ground blast furnace slag added to the cement was $20-50 \%$. The filling test blocks of all proportions were demolded within 24-36 h, and the integrity of the formed filling bodies was satisfactory. Among them, the uniaxial compressive strength of the test block formed by the filling slurry with a tailings-to-cement ratio of $3 / 1$ and a concentration of $74 \%$ after 3 , 7,28 , and 60 days reached $0.833,2.026,4.520$, and $6.560 \mathrm{MPa}$, respectively. The strengths of the other filling blocks also met the engineering design requirements. Based on the statistical regression analysis method, the influences of the slag cement content $\chi_{1}$ and the tailings water content $\chi_{2}$ on the filling body's strength $\sigma$ were analyzed. The regression calculation also considered the interaction between $\chi_{1}$ and $\chi_{2}$, and the obtained multiple nonlinear regression model successfully predicted $\sigma$. In production and application, the large density of tailings would accelerate their settling, which could easily cause blockage during the transportation of filling slurry through the pipeline. Regarding a series of existing filling materials and technical conditions, the filling process investigated in this study overcomes several unfavorable conditions. Using advanced and reliable technology and an industrial filling pump with a delivery pressure of $10 \mathrm{MPa}$, the prepared filling slurry concentration was $68-72 \%$ and the flow rate was $56-79 \mathrm{~m}^{3} / \mathrm{h}$. The tailings and PSA42.5 Portland slag cement combined quite well. The filling body in the goaf demonstrated excellent homogeneity, and the various industrial indicators met the technical requirements for mining deposits. The preparation of highquality filling materials with a smooth filling process has played a positive role in the prevention and treatment of surface mountain cracks and collapse during underground mining in high-altitude areas.

Keywords: high-altitude mine, portland slag cement, surface collapse and damage, blast furnace slag, environmental protection 


\section{INTRODUCTION}

When using a mine's own tailings for goaf filling, the supply of tailings should be convenient and sufficient. In addition, the physical and mechanical properties of the cemented filling materials should satisfy the technical requirements and should ultimately have a certain technological and economic competitiveness (Behera et al., 2019; Zheng and Li, 2020). In the search for technically feasible, safe, and reliable filling materials, many recent studies have conducted relevant filling material development and performance analysis, and they have achieved some progress in developing economically viable filling materials (Chen et al., 2020; Li et al., 2020). For example, in terms of block stone cemented filling materials, several studies have optimized the gradation of the waste rock produced during the mining process, compared and verified the combination of different tailings and stone contents, and obtained a filling material with a better density (Wu et al., 2021). In the highgrade iron ore mining process in the Ukrainian PJSC zaporizhzha and Pivdenno-Bilozerske mines, cemented rock fill materials were used for goaf filling, which provided stable surrounding rock conditions for safe production, reduced industrial waste emissions, and inhibited surface subsidence hazards (Oleg et al., 2021). To obtain filling materials with stable mechanical properties, several researchers have comprehensively studied the interaction between cemented filling bodies and rock interfaces, analyzed the factors influencing the fracture toughness, and established a theoretical basis for the resource utilization of mining solid waste (Fang and Mamadou, 2020). In the treatment of ultra-fine particle tailing backfill materials, some researchers have adopted the method of flocculation and sedimentation of fine-particle tailings to accelerate the concentration of the tailings. This enabled the fine particle tailing mortar to reach the concentration required for the process in a shorter period. Combining the filling mortar and cementitious materials in a certain ratio can form a filling body with a strength suitable for the mining approach, thereby creating feasible conditions for the preparation of the filling slurry (Cui, 2018; Zhao et al., 2020).

When using tailings and cementitious materials to prepare a filling slurry, due to the particularity of the physical and chemical properties of the tailings, the mechanical properties of the filling formed by the combination of fine particle tailings and cementitious materials are less ideal, and the low strength of the filling body will affect the subsequent mining process ( $\mathrm{Na}$ et al., 2021; chao et al., 2020). For example, the low strength of the filling body can cause many safety problems in the roof of the large section of roadway and in the chamber roof in the high stress area. The filling body can collapse after being exposed through mining of the adjacent pillar. This can affect the ore extraction operation of the scraper and the subsequent ore grade, which can in turn reduce the beneficiation efficiency and increase the beneficiation costs. The filling slurry cannot become consolidated and harden normally for a long time after entering the goaf, which can cause the filling retaining wall to exhibit excessive hydrostatic pressure and potentially crack. To address these problems, several researchers have optimized and developed filling materials for the specific conditions of mine filling projects (Ouattara et al., 2018; Zhang et al., 2020). In studies focused on improving the strength of the filling body, researchers have optimized the combination of different filling aggregates. Based on theoretical analysis and experimental verification, the densities and mechanical strengths of the filling materials were improved, and the effect of the filling bodies on maintaining the stability of the rock formation was also improved (Wenbin et al., 2021; Zhang et al., 2021). In the evaluation of the in-situ performance of cement paste, researchers have developed a curing under applied pressure system (CUAPS) to understand the consolidation behavior of in-situ cement paste materials in field tests (Bruno et al., 2010). In split Hopkinson pressure bar (SHPB) tests of the dynamic mechanical behavior of cemented backfill materials, it has been shown that the failure mode of cemented backfill materials is similar to that of lowstrength concrete. This finding can be used to guide the strength design of deep mining backfill (Tan et al., 2019). For a similar case, another study tested the geotechnical characteristics of peatbased cover materials. The test items included the properties of compaction, consolidation, and hydraulic and thermal conductivities. These methods provide a reference for studies of the performances of filling bodies (Khoshand and Fall, 2016).

The stability of the backfill is an important part of the backfill's stop design. A good backfill can effectively protect the pillar and roof from being damaged. In view of the stability of the backfill, some researchers have determined the aspect ratio $\mathrm{H} / \mathrm{B}$ of the stope workspace and have verified the calculations through field implementation (Li and Aubertin, 2012). Based on a dynamic model of blasting vibration monitoring of mine backfill and field instruments, it is possible to use blasting vibration data to understand the state of the backfill, which can be used to effectively deal with the adverse consequences of backfill damage (Emad et al., 2018). Regarding the influence of blasting vibrations on filling damage, several researchers have used dynamic numerical simulations to characterize the blasting vibrations and have confirmed that they are the main reason for the wedge-shaped damage to the filling body (Zaka and MitriHani, 2014). In terms of blasting vibration damage of cemented rock fill (CRF), related studies have utilized monitoring blasting vibrations to evaluate the stability of CRF and have provided a theoretical basis for related drilling and blasting mining design (Emad et al., 2015). In terms of improving the stability of the filling body, a previous study adopted several feasible techniques to strengthen the filling body, which greatly reduced the probability of the collapse of the filling body (Emad et al., 2012). For example, in terms of shortening the consolidation and hardening time of the cemented filling slurry, the addition of fillers/additives and microscopic analysis provided a basis for accelerating the consolidation and hardening of the filling slurry (Belem et al., 2001; Benzaazoua et al., 2004; XU et al., 2017). Regarding cemented backfill with a high sulfur content, some researchers have analyzed multiple aspects (involving physics, chemistry, and mineralogy) and proposed feasible ideas for improving the performance of the backfill (Benzaazoua et al., 1999). Regarding the influence of sulfaterich mine water on the mechanical behavior of cemented paste 
backfill (CPB), researchers have immersed CPB samples in sulfate solutions of different concentrations $(0,0.1,1$, and $10 \mathrm{~g} / \mathrm{L})$. By testing the strength of each curing time, the microstructure changes of the CPB were observed. This study revealed the significant influence of the sulfate concentration on the formation and crystallization of hydration products and provided several reasonable suggestions for the engineering design of goaf filling (Belem et al., 2000).

To make full use of the limited mineral resources, properly disposing of the solid waste generated in the production processes in metal and non-metal mines can avoid subsequent environmental pollution and achieve safe production of mineral deposits. As an important means of preventing and managing the potential risks of environmental pollution in mines, the current filling mining technique has become one of the main techniques used in various mines (Deng et al., 2014). In the mining of deep mineral resources, in the face of more complex rock mechanics conditions, underground mining can encounter many unknown difficulties. Thus, it is essential to improve goaf filling and its maintenance in order to create a safe working environment for daily production (Cai and Brown, 2017). Among various mining methods, the filling method combines the output of coal gangue or tailings with the formation of the goaf, creating a circular relationship between the supply and demand. The feedback is to provide enterprises with a positive state of environmental safety and efficient ore recovery ( $\mathrm{Lu}$ and Fall, 2018). In view of the many advantages of backfill mining, the related research has gradually received extensive attention (for both metal and non-metal mines), and scientific research on the properties of various materials and engineering conditions is making positive progress (Sun and Ren, 2012). The Huashugou copper mine in the Jingtieshan mining area of the Jiuquan Iron and Steel Group in Gansu Province is a high mountain area located in the western part of the North Qilian Mountains, with an altitude of 2,700-3,200 m, a relative elevation difference of about $500 \mathrm{~m}$, and an average slope of $48^{\circ}$. To better recover the copper resources, filling mining was implemented in the Huashugou copper mine to mine the ore body in order to achieve the purpose of timely backfilling of the goaf and reducing the tailings discharge (Liang et al., 2013; Wang, 2013; Ran et al., 2014). From the perspective of environmental protection and comprehensive utilization of minerals, the application of this approach has played a positive role in the sustainable development of mines.

\section{MATERIALS AND METHODS}

\section{Tailings}

The experiments used tailings as the aggregate of the filling materials. The tailings were obtained from the copper concentrator plant (with an annual copper ore processing capacity of $300,000 t$ ) of the Jingtieshan iron mine. In order to easily obtain the typical tailing samples on site, the tailing mortar was discharged into several $75 \mathrm{~L}$ plastic buckets with DN50 plastic pipes at different time intervals during the normal operation of the mine's concentrator for 3-5 days. After filling the plastic

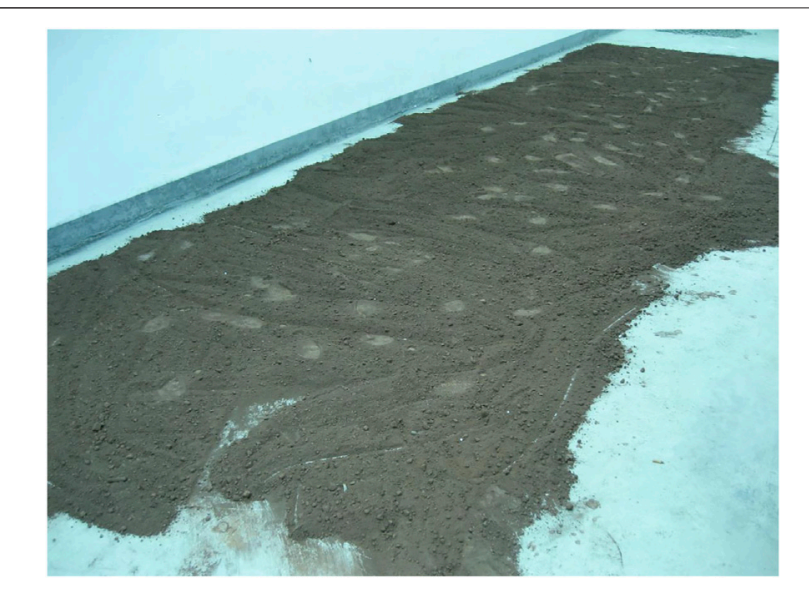

FIGURE 1 | The tailing was dried in the laboratory.

buckets with low concentrations of tailing mortar, the plastic buckets were gradually tilted after a period of natural sedimentation (until the tailing particles no longer moved and settled) to allow the water in the upper part of the buckets to flow out slowly. To make the sampled tailings more representative, the operation of this process needs to be stable and orderly to avoid the loss of fine particle tailings. The tailings in each plastic bucket were collected and bagged in three layers of woven bags with inner bile. After completing the sample collection, all of the samples were transported by car to the laboratory in Changsha. In preparation for the experiments, all of the samples were oven-dried, sun-dried, and evenly mixed. Before test, the tailing was naturally dried in the laboratory, as shown in Figure 1.

To ensure that the test results were representative, the sundried tailings used for the physical and chemical properties test were sampled using the quartile method. The physical properties of the tailings have a great impact on the performance of the filling materials. After several multi-point sampling measurements, representative data were obtained. The measurement results for the commonly used physical properties are presented in Table $\mathbf{1}$. The chemical composition of tailings is shown in Figure 2. After even mixing, the particle size distribution of the tailings was measured using a Malvern 2000 laser particle size analyzer. The particle size distribution is presented in Figure3.

Combined with the on-site filling process, because the concentration of tailing delivered from the copper concentrator plant to the filling station is about $40 \%$, so in this paper the tailings were mixed with an appropriate amount of water to prepare a tailing mortar with a concentration of $40 \%$. The natural sedimentation parameters of the tailing mortar were measured. For more close to the actual production situation, the changes in the final concentration and bulk density of the tailings mortar after $24 \mathrm{~h}$ of natural sedimentation are displayed in Figure 4. As shown in Figure 4A, the sedimentation concentration of tailings with initial concentration of $40 \%$ increase with time. The concentration is linear with 
TABLE 1 | Test results of the physical properties of the tailings.

\begin{tabular}{|c|c|c|c|c|c|}
\hline Density & $\begin{array}{l}\text { Loose bulk } \\
\text { density }\left(t / \mathrm{m}^{3}\right)\end{array}$ & $\begin{array}{l}\text { Compacted bulk } \\
\text { density }\left(t / \mathrm{m}^{3}\right)\end{array}$ & $\begin{array}{c}\text { Maximum porosity } \\
(\%)\end{array}$ & $\begin{array}{c}\text { Minimum porosity } \\
(\%)\end{array}$ & $\begin{array}{l}\text { Angle of } \\
\text { repose ( }\left(^{(}\right)\end{array}$ \\
\hline 2.963 & 1.298 & 1.695 & 56.19 & 42.79 & 38.9 \\
\hline
\end{tabular}

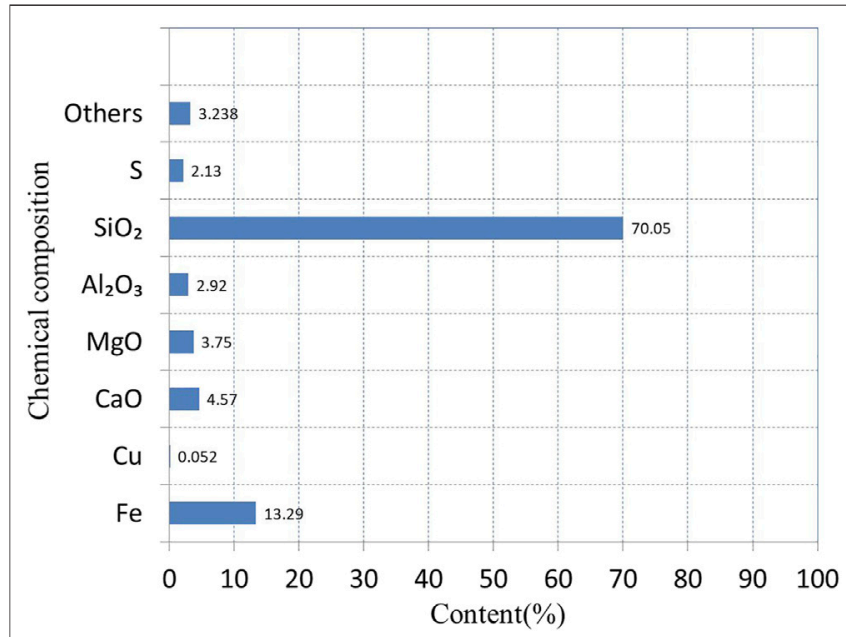

FIGURE 2 | Chemical composition of tailings.

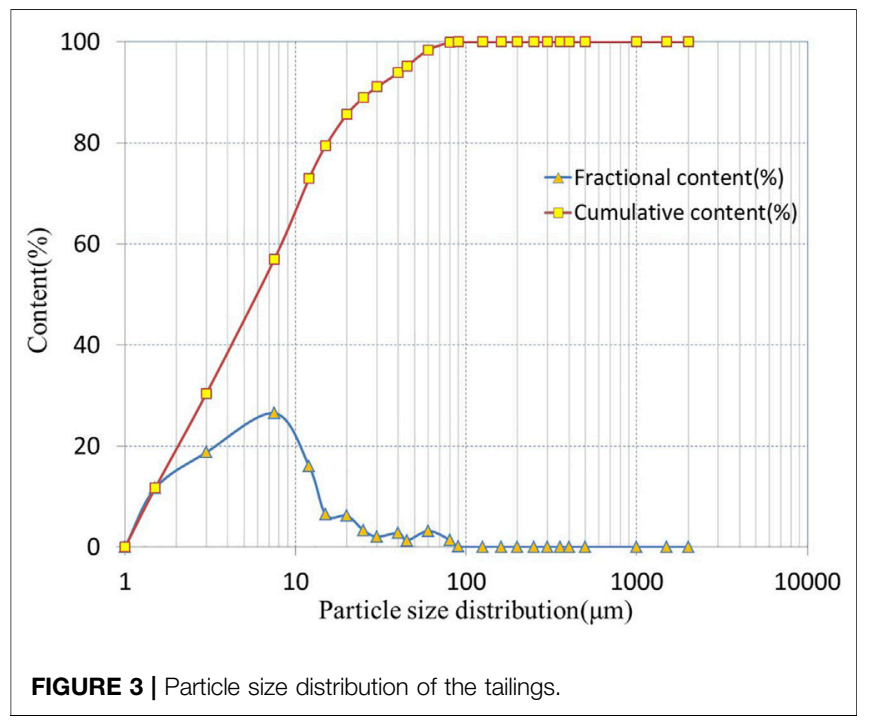

sedimentation time from 1 to $600 \mathrm{~s}$. The settling velocity of the tailing mortar is obviously accelerated, the trend of settling curve becomes steeper, inflection point of rise appears, and the settling concentration increases greatly from 600 to $1150 \mathrm{~s}$. After $1,150 \mathrm{~s}$, the settlement velocity slows down and reaches the final settlement state. The settlement concentration is close to $67.7 \%$ after $24 \mathrm{~h}$. As can be seen from the curve in Figure 4B, the settlement bulk density basically follows the same variation

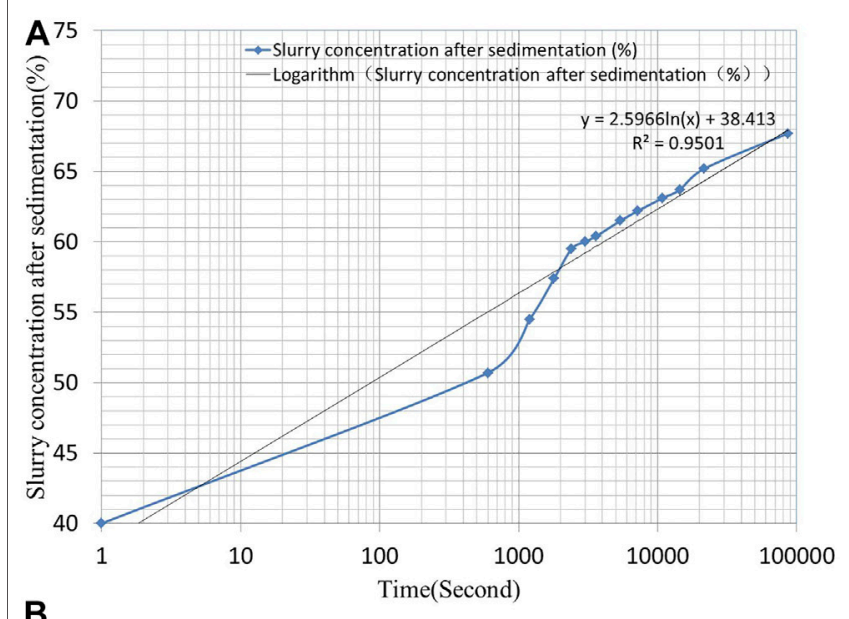

B

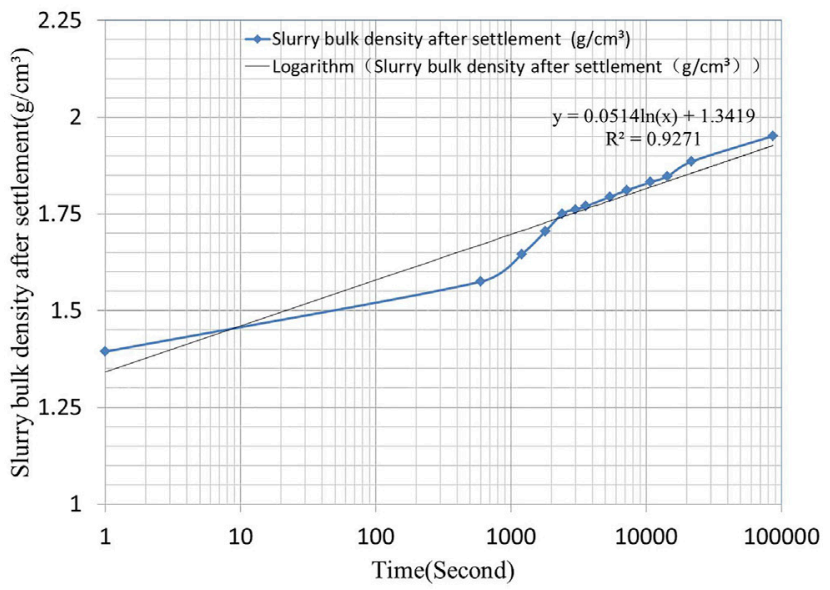

FIGURE 4 | Changes in the slurry concentration and bulk density.

trend as the settlement concentration. Similarly, after $24 \mathrm{~h}$ of natural settlement, the settlement bulk density is $1.951 \mathrm{~g} / \mathrm{cm}^{3}$.

\section{Cement}

In the proportioning test, we used cement as the filling and cementing material. The cement named as Gobi P.S.A 42.5 Portland slag cement was produced by the Hongda Building Materials Co., Ltd., JISCO Group. After sampling the standard packaged cement, a series of laboratory tests was conducted to determine the properties of the cement, (e.g., density, loose bulk density, compacted bulk density, and angle of repose of natural accumulation). Then, the maximum and minimum porosities were calculated. The chemical composition of cement is shown in 


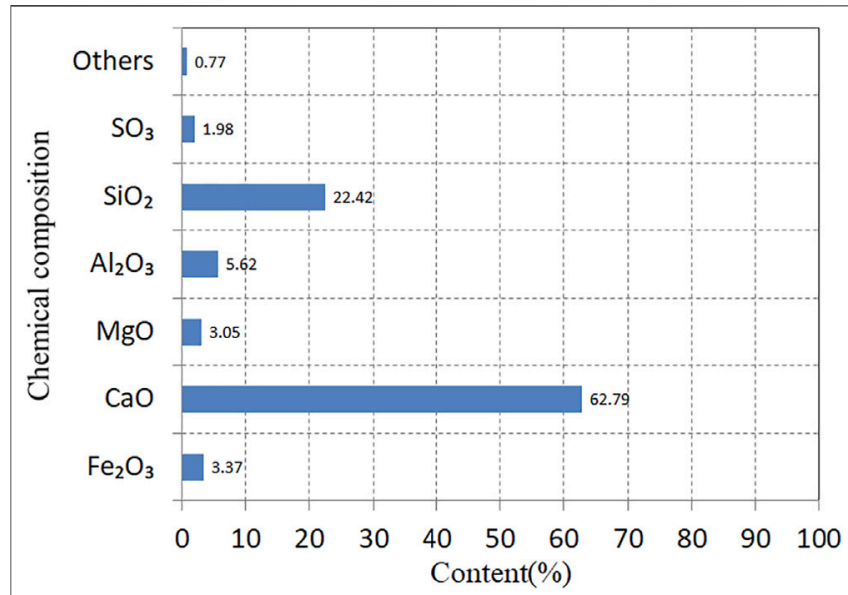

FIGURE 5 | The chemical composition of cement.

Figure 5. Through testing and data analysis, the basic physical properties of the cement were obtained (Table 2).

\section{Tailings Water}

The water used to make the cemented filling test blocks was the tailing water discharged from the Jingtieshan Copper Mine Concentrator. After the basic performance index tests, the density of the tailings water after beneficiation is basically $1 \mathrm{~g} /$ $\mathrm{cm}^{3}$, the $\mathrm{pH}$ value is about 6.9. The water was neutral, and the water temperature during the test was $18-22^{\circ} \mathrm{C}$. The collection of tailing water is shown in Figure 6.

\section{LABORATORY FILLING SLURRY PREPARATION AND FILLING BODY PERFORMANCE TESTS}

\section{Filling Slurry}

In the proportioning test of the filling materials conducted in the laboratory, the tailings from the copper concentrator were used as the filling aggregate. Gobi brand P.S.A42.5 Portland slag cement was used as the filling and cementing material; and the water used to make the test blocks was the tailings water from the concentrator. Combined with the mining conditions of the deposit, according to the main factors affecting the mechanical properties of the filling materials and the slurry flow performance during the transportation process, the tests included three groups of filling slurry with concentrations of $70-74 \%$ at equal intervals, and four tailings-to-cement ratios of 3:1, 4:1, 6:1, and 8:1. Since the test materials were all fine-grained materials, the size of the test blocks were cubes with a side length of $70.7 \mathrm{~mm}$. After

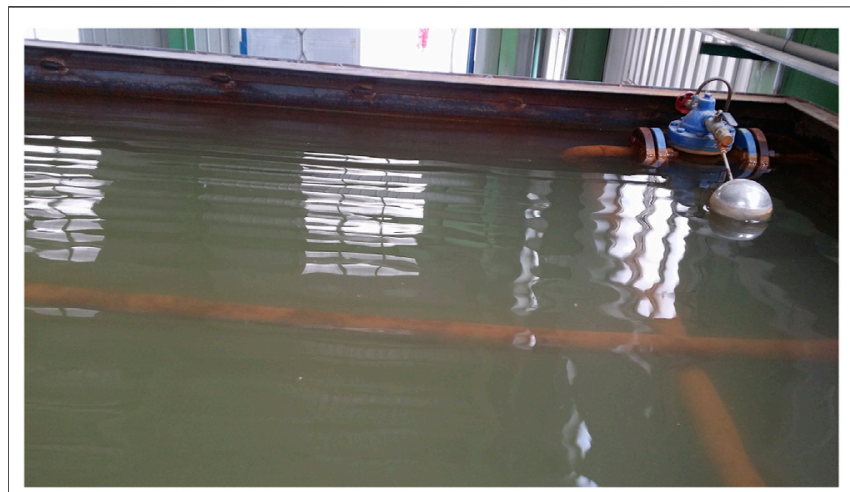

FIGURE 6 | The cistern of tailing water.

loading all of the materials into the same container and mixing evenly, the test blocks were poured in stages and placed statically. Stage controlled backfilling method is adopted and then the strength of filling body is not strict. Therefore, in the process of laboratory test, the fabricated test block was demolded within 24-36 h, which did not affect the mining technology requirements. The text blocks were demolded according to the consolidation and hardening conditions (more than $24 \mathrm{~h}$ ), and the temperature of the laboratory curing box was adjusted to $18-22^{\circ} \mathrm{C}$. After regular moisturizing and curing at the corresponding times, we used an NYL-300 concrete compression testing machine to test the uniaxial compressive strength of each test block.

By combining the basic physical properties of the test materials, the bulk density parameters of the filling slurry were calculated. The material preparation and consumption of the test materials are presented in Table 3. The materials were uniformly mixed in the laboratory, and the filling slurry after fully mixing is shown in Figure 7A. A filling test block made using the triple concrete test mold is shown in Figure 7B.

\section{Filling Performance Tests}

After curing the cemented filling body test blocks in the curing box for 3, 7, 28, and 60 days, the test blocks were taken out of the curing box. The unconfined uniaxial compressive strengths of the filling body test blocks corresponding to each curing time were tested. The strength parameters of the different filling body test blocks were obtained through experiments. After summarizing and sorting, mathematical methods were used to perform statistical analysis, and the variation in the strength of the filling body under different conditions was analyzed. By keeping the tailings-to-cement ratio of the filling material constant, the variation in the strength of the test blocks of each concentration and curing time is shown in Figure 8.

TABLE 2 | Measurement of the physical properties of the cement.

\begin{tabular}{lcccc}
\hline Density & $\begin{array}{c}\text { Loose bulk } \\
\text { density }\left(\mathbf{t} / \mathbf{m}^{\mathbf{3}}\right)\end{array}$ & $\begin{array}{c}\text { Compacted bulk } \\
\text { density }\left(\mathbf{t} / \mathbf{m}^{\mathbf{3}}\right)\end{array}$ & $\begin{array}{c}\text { Maximum porosity } \\
(\%)\end{array}$ & $\begin{array}{c}\text { Minimum porosity } \\
(\%)\end{array}$ \\
\hline 3.132 & 1.298 & 1.785 & 58.55 & 43.01 \\
\hline
\end{tabular}


TABLE 3 | Preparation and consumption of the filling materials.

\begin{tabular}{|c|c|c|c|c|c|c|c|}
\hline \multirow[t]{2}{*}{ No. } & \multirow[t]{2}{*}{ Water/cement } & \multirow[t]{2}{*}{ Cement/tailings } & \multirow{2}{*}{$\begin{array}{c}\text { Water/(cement + } \\
\text { tailings) }\end{array}$} & \multirow{2}{*}{$\begin{array}{l}\text { Bulk density } \\
\qquad\left(\mathrm{t} / \mathrm{m}^{3}\right)\end{array}$} & \multicolumn{3}{|c|}{ Material consumption $\left(\mathrm{kg} / \mathrm{m}^{3}\right)$} \\
\hline & & & & & Water & Tailings & Cement \\
\hline 1 & 1.714 & 0.333 & 0.428 & 1.876 & 563 & 985 & 328 \\
\hline 2 & 1.555 & 0.333 & 0.389 & 1.924 & 539 & 1,039 & 346 \\
\hline 3 & 1.405 & 0.333 & 0.351 & 1.975 & 513 & 1,096 & 365 \\
\hline 4 & 2.142 & 0.250 & 0.428 & 1.874 & 562 & 1,049 & 262 \\
\hline 5 & 1.944 & 0.250 & 0.389 & 1.922 & 538 & 1,107 & 277 \\
\hline 6 & 1.756 & 0.250 & 0.351 & 1.972 & 513 & 1,168 & 292 \\
\hline 7 & 3.000 & 0.167 & 0.428 & 1.871 & 561 & 1,123 & 187 \\
\hline 8 & 2.722 & 0.167 & 0.389 & 1.919 & 537 & 1,184 & 197 \\
\hline 9 & 2.459 & 0.167 & 0.351 & 1.969 & 512 & 1,249 & 208 \\
\hline 10 & 3.857 & 0.125 & 0.428 & 1.870 & 561 & 1,163 & 145 \\
\hline 11 & 3.500 & 0.125 & 0.389 & 1.917 & 537 & 1,227 & 153 \\
\hline 12 & 3.162 & 0.125 & 0.351 & 1.968 & 512 & 1,294 & 162 \\
\hline
\end{tabular}

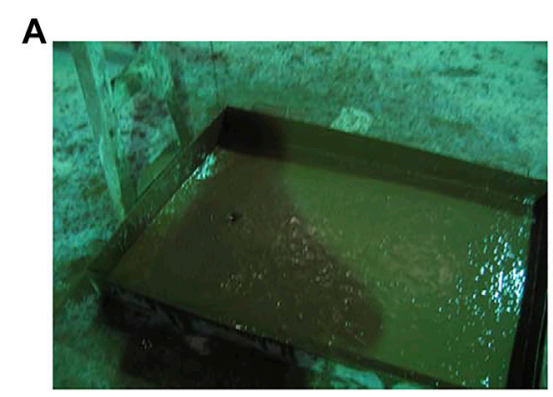

Fully-stirred filling slurry

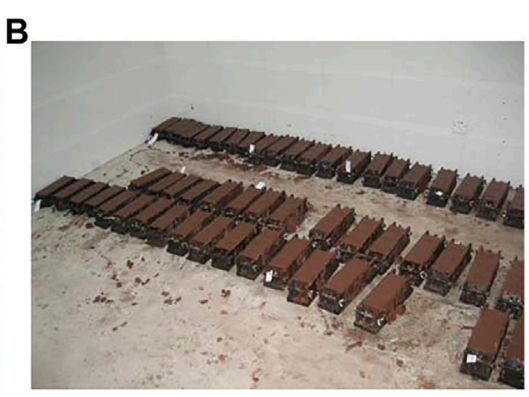

Filling test block for pouring the test mold

FIGURE 7 | Filling slurry stirring and test block production.

When the concentration of the filling slurry is kept constant, the change in the strength of the test block for each curing time with a given tailings-to-cement ratio is presented in Figure 9. For the filling test blocks with the same curing time, the variation in the strength of the test blocks of each concentration with the tailingsto-cement ratio is illustrated in Figure 10.

To understand the influences of the different factors on the strength of the filling body, the cement-tailings ratio $\chi_{1}$ and the concentration of the filling slurry $\chi_{2}$ were taken as independent variables, and the interaction between the cement-tailings ratio $\chi_{1}$ and the concentration of the filling slurry $\chi_{2}$ was also considered. In addition, the day 3, day 7, day 28, and day 60 uniaxial compressive strengths of the test blocks $\sigma_{03}, \sigma_{07}, \sigma_{28}$, and $\sigma_{60}$ were used as dependent variables. At the initial stage of the original data induction and arrangement, the relevant data should be listed in the spreadsheet. The strength of the backfill corresponding to the specific cement-sand ratio and the concentration of the backfill slurry should be listed. The strength samples at the same curing age should be grouped into a column to clarify the strict correspondence between the data. Using data processing methods similar to those described in previous studies, the statistical regression analysis of the test parameters was performed using mathematical software, e.g., Excel or Matlab (Quan et al., 2007; Qiao et al., 2019; de Souza et al., 2021; Freise et al., 2021). Regression statistical analysis is shown in Table 4. The analytical relationships between the uniaxial compressive strength and the influencing factors of each group of filling test blocks were established. The obtained multiple regression equation for the strength of the filling body is presented in Table 5.

\section{FIELD FILLING INDUSTRIAL TEST AND RESULT ANALYSIS}

\section{Field Filling Industrial Test}

In the industrial testing stage of the filling, when the tailings entering process was completed, after a period of natural sedimentation, the concentration of the tailing mortar was increased after deposition. A certain amount of water was secreted from the upper part, and the sidewalls of the tailings silo were opened row by row from top to bottom. The stepped drain valve gradually drained part of the clarified water from the upper part of the tailings mortar, leaving some for the slurry adjustment and concentration adjustment. Then, the air compressor was turned on to compress the tailings mortar in the horizontal sand silo. After about 40-50 min, the tailings mortar throughout the entire horizontal sand silo exhibited a uniform boiling state and became a porridge-like fluid, which rolled up and down due to the agitation of the bubbles. At this 


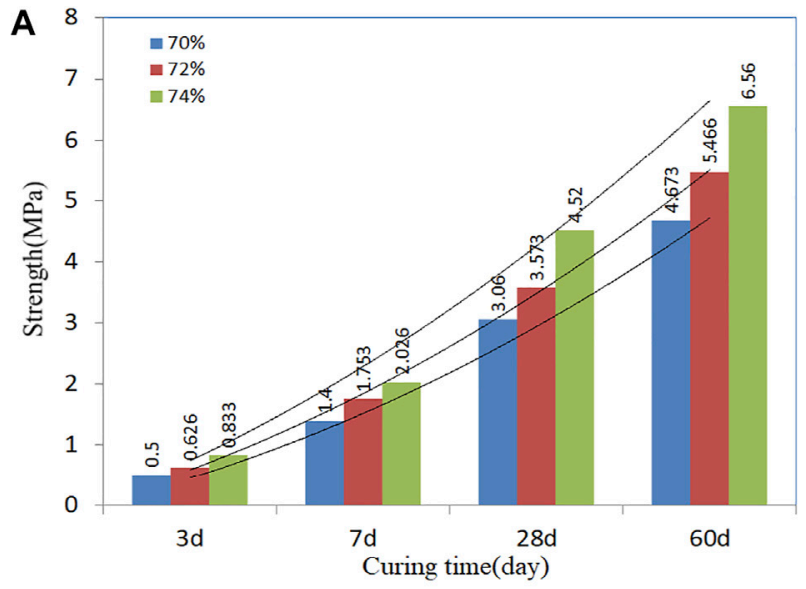

B

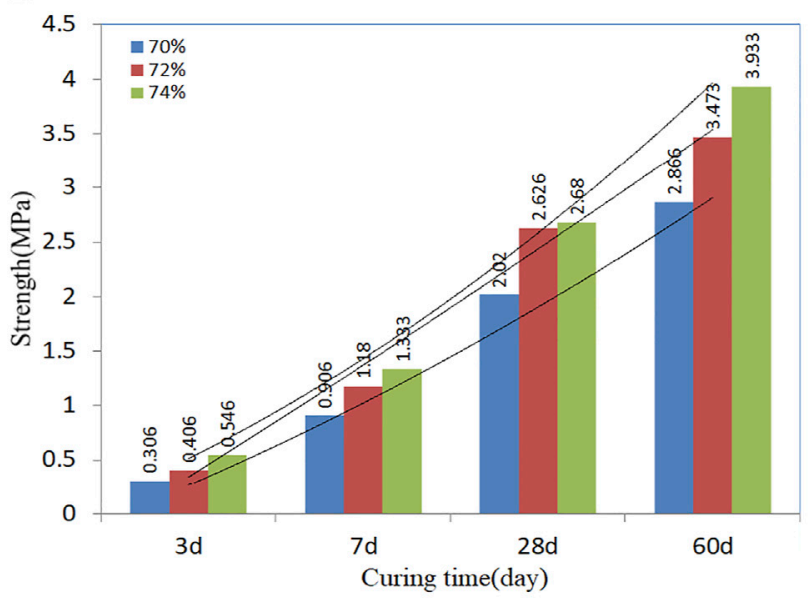

(b) Tailings/Cement $=4 / 1$

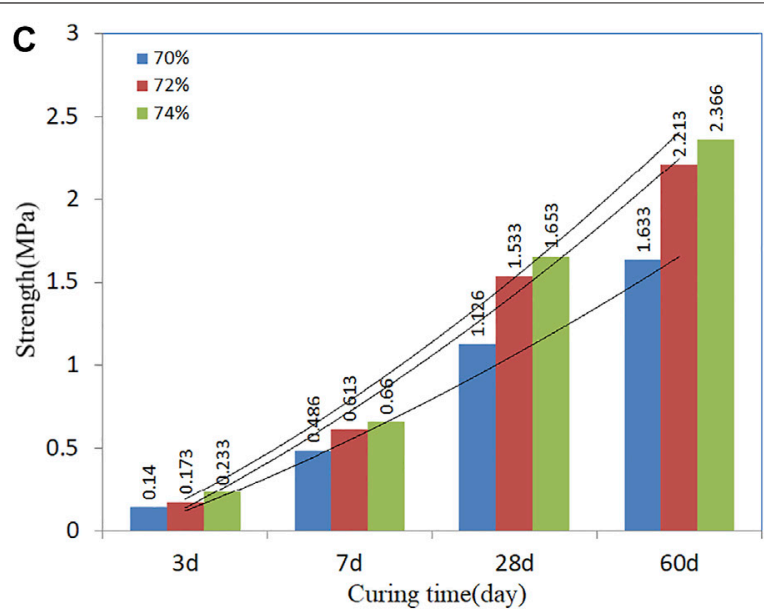

(c) Tailings/Cement=6/1

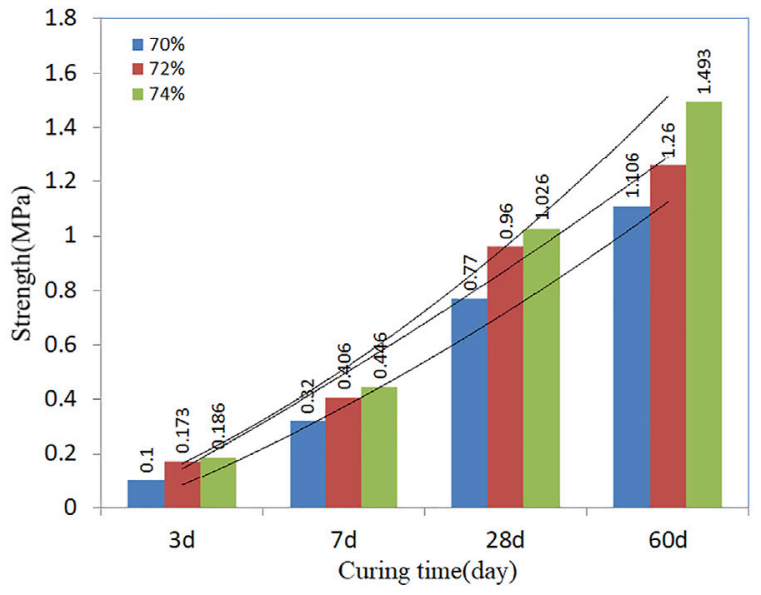

(d) Tailings/Cement $=6 / 1$

FIGURE $\mathbf{8}$ | Change in the strengths of the test blocks with different concentrations with curing time for a given tailings-to-cement ratio.

time, the liquefaction of the tailings mortar was completely uniform. Then, the sand discharge valve at the bottom of the horizontal sand silo was opened to discharge the sand. The flow chat of filling process is shown in Figure 11.

The uniform activation and stirring of the two-stage mixer after the addition of the cement enabled the filling slurry to flow into the suction tank of the filling industrial pump. After being pressurized by the filling industrial pump, it was transported to the distant goaf for cementation and filling. The first phase filling slurry preparation station was located in a huge mountain with an altitude of $+2,880 \mathrm{~m}$. The equipment in the filling slurry preparation station was located in a large rock chamber. The equipment in the chamber is shown in Figure 12. The underground cement silo fed the horizontal mixer through a screw conveyor and an electronic scale. The cement silo and screw conveyor are shown in Figure 13. The connecting roadway at the end of the goaf was filled with a brick filling retaining wall. Three DN150 pipelines were installed on the retaining wall as observation tubes.

\section{Filling Operation and Result Analysis}

Throughout the period of filling operations and adjustments, the downhole filling system underwent a smooth process and the technical conditions were sufficient for long-term operation. When the material supply was sufficient, the filling system fully satisfied the filling capacity requirements of the goaf generated by the mining and a separation capacity of 300,000 t/a of copper ore. The horizontal sand silo had a sand concentration of $40-47 \%$. After $8-12 \mathrm{~h}$ of flocculation and sedimentation, the sand concentration basically stabilized at about $65-69 \%$ for a long time. The flow rate was controlled at around $65-75 \mathrm{~m}^{3} / \mathrm{h}$ through the control valve, and the concentration of the filling slurry was approximately $71 \%$. After adding PSA42.5 Portland slag cement, the hydration reaction of the cement was sufficient, and the flow rate of the filling slurry after the addition of the cement also increased. When the filling slurry passed through the filling retaining wall, a higher tailings-to-cement ratio of 3:1-4:1 was used (i.e., the cement content of the dry material was 25-20\%), and the increase in the height of the filling slurry level was controlled 


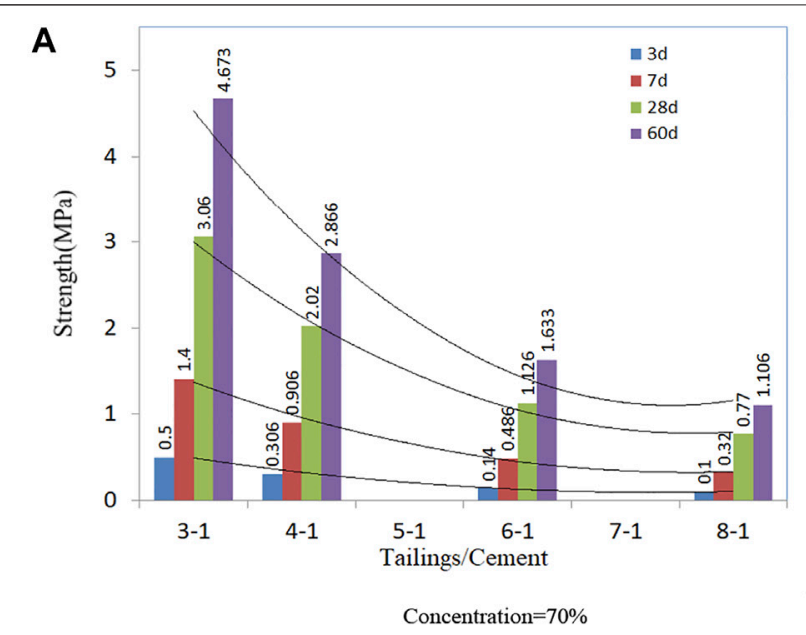

B

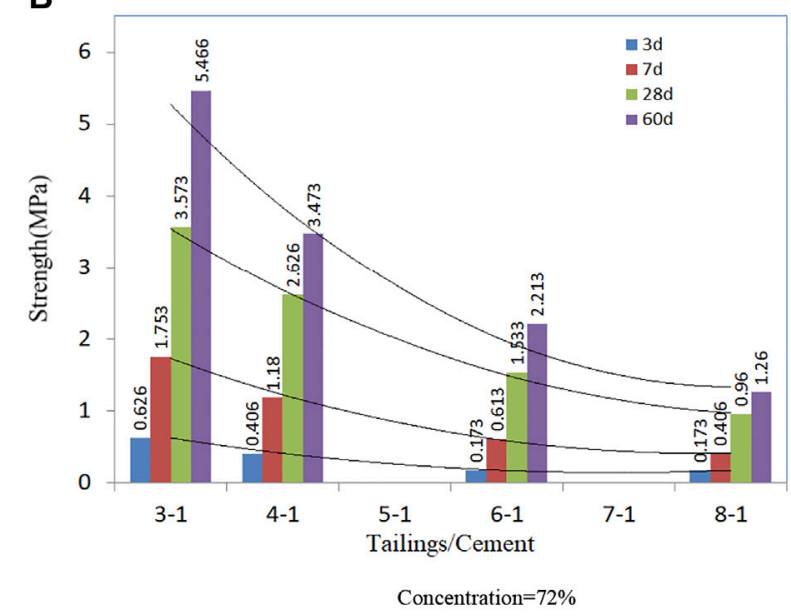

C

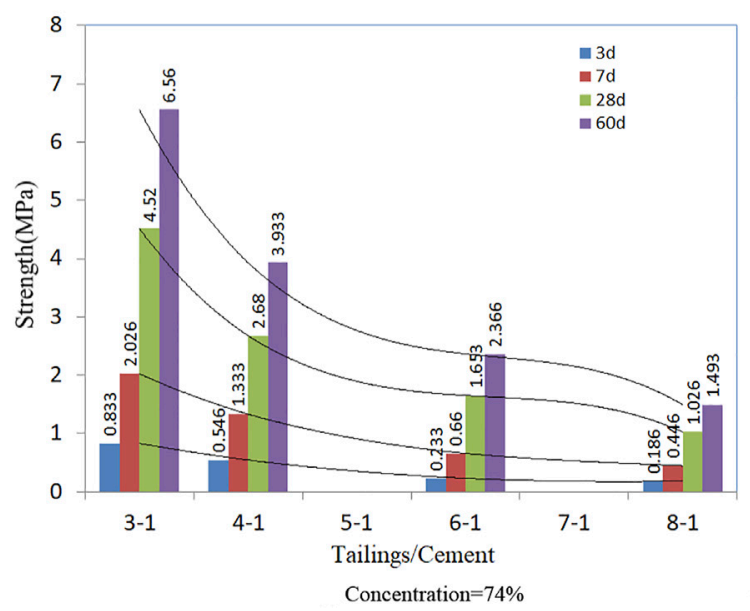

FIGURE 9 | Change in the strength of the test blocks with the tailings-tocement ratio at different curing times for a given concentration.

at $1.85-2.25 \mathrm{~m}$. In each stage of the filling operation, there was no slurry leakage around the filling retaining wall, indicating that the surface of the filling retaining wall and the surrounding rock wall were maintained by the M7.5 sprayed cement mortar. The cracks were filled, and it was difficult for the water in the filling slurry to flow out of the periphery. Thus, the filling retaining wall was relatively stable.

After several episodes of operation and adjustment, the filling system was able to operate stably for a long time. For the case of two $8 \mathrm{~h}$ shifts per day, the working conditions of the equipment were good and the filling efficiency was fully reflected. By measuring the exposed filling body within a height of $1.5-8 \mathrm{~m}$ from the bottom, the strength of the filling body test block was determined to be $2.75-4.65 \mathrm{MPa}$. The integrity of the filling body was intact, and its color was grayish brown and grayish white. The filling body did not collapse when the self-standing height exceeded $20 \mathrm{~m}$. From the perspective of the fracture feel of the unexposed part, the filling body was relatively hard and dense, with a bulk density of about $1.87-2.15 \mathrm{~g} / \mathrm{cm}^{3}$. An accidental shutdown was caused by a cement supply problem, and the production had to be suspended. This means that when the supply of various filling materials is sufficient, the filling system can operate for a long time.

\section{DISCUSSION}

1) On the basis of uniform sampling and testing, the relevant physical properties of the copper flotation tailings were obtained. According to the results of the laser particle size tests, the content of the $7.5 \mu \mathrm{m}$ particles in the tailings from the Huashugou copper mine was relatively high, with fractional and cumulative contents of 26.53 and $56.99 \%$, respectively. The fractional and cumulative contents of the $15 \mu \mathrm{m}$ particles were 6.46 and $79.46 \%$, respectively. The fractional and cumulative contents of the $80 \mu \mathrm{m}$ particles were 1.43 and $99.88 \%$, respectively. When the particle size was $90 \mu \mathrm{m}$, the cumulative content of the particles reached $100 \%$. Therefore, the tailings were extremely fine-grained tailings (i.e., less than $90 \mu \mathrm{m}$ ). In the pipeline transportation process, very fine particle tailings typically have a strong viscosity, so the tailings can easily adhere to the pipe wall and reduce the cross-sectional area of the transportation pipeline. At this time, the transportation pipeline's pressure will increase sharply. In the process of selecting a filling slurry conveying pump, after considering this problem, an industrial filling pump with an outlet pressure of greater than $10 \mathrm{MPa}$ was selected. Based on the daily production situation, the prepared filling slurry delivery conditions were normal. The conveying flow and pressure were normal and stable. In the preliminary filling process, the height difference of the filling pipeline is not large, and the conveying distance is about $450-1,000 \mathrm{~m}$. With the increase of the mining depth, the conveying resistance of the filling slurry will be further reduced. Therefore, the filling industrial pump with the outlet pressure of $10 \mathrm{MPa}$ can meet the technical requirements of the filling process.

2) During the natural sedimentation of the tailings with an initial concentration of $40 \%$, as the settling time increased, due to the combined actions of gravity and buoyancy of the tailings 

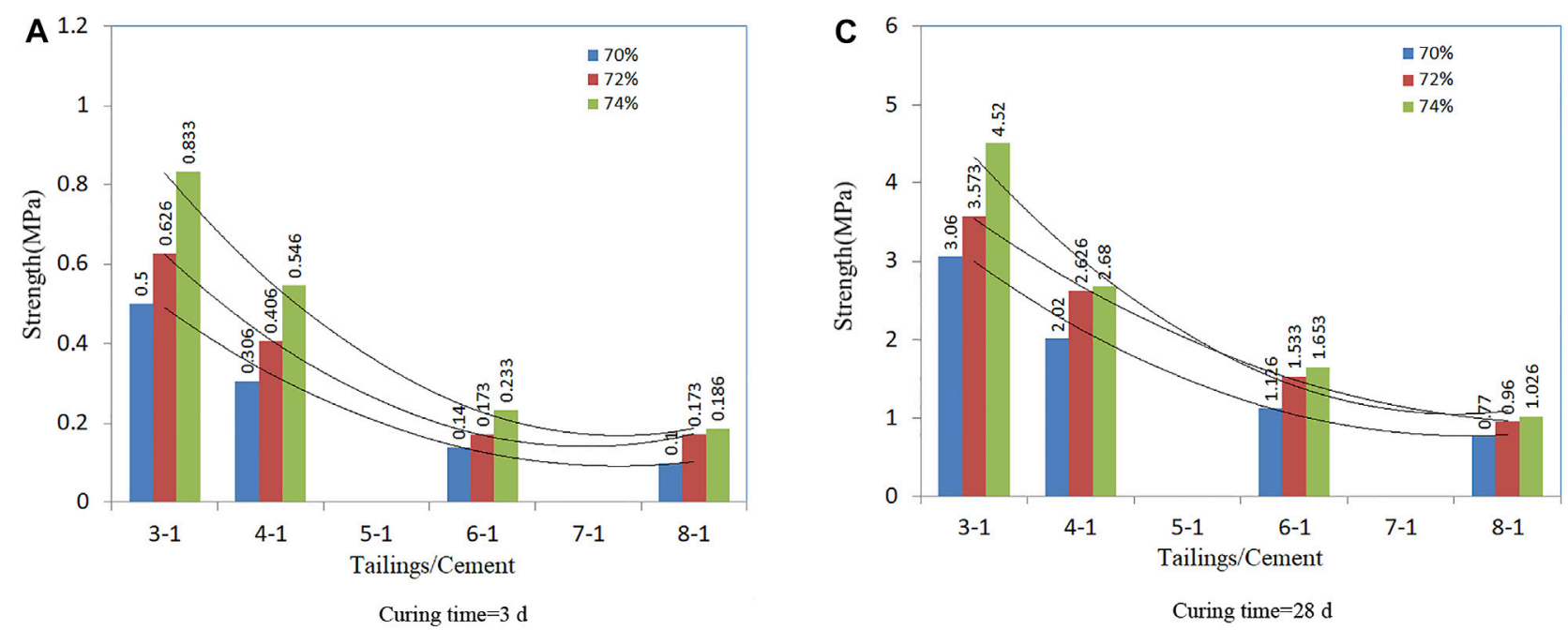

B
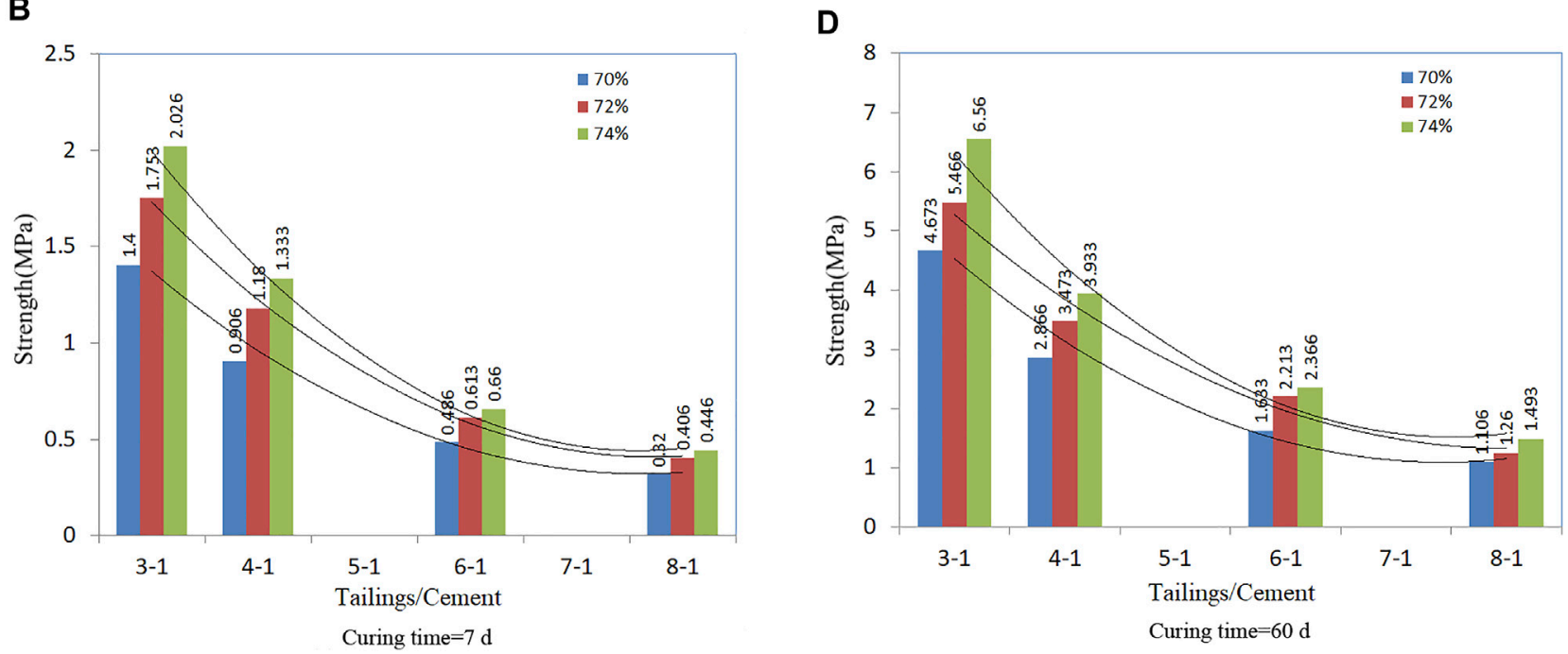

FIGURE 10 | Change in the strength of test blocks with different concentrations with tailings-to-cement ratios for a given curing time.

TABLE 4 | Regression statistics.

\begin{tabular}{lcccc} 
Regression analysis & $\sigma_{03}$ & $\sigma_{07}$ & $\sigma_{28}$ & $\sigma_{60}$ \\
\hline Multiple R & 0.996592 & 0.995982 & 0.986532 & 0.989930 \\
$R^{2}$ & 0.993196 & 0.991981 & 0.973245 & 0.979961 \\
Adjusted $R^{2}$ & 0.986393 & 0.983962 & 0.946489 & 0.959922 \\
Standard error & 0.027637 & 0.073348 & 0.276656 & 0.355912 \\
Observed value & 11 & 11 & 11 & 11 \\
\hline
\end{tabular}

particles, the initial slurry buoyancy was small due to the low concentration, so the tailings particles settled faster. As the slurry concentration continued to increase, the buoyancy of the slurry caused by the tailings particles during the sedimentation process also increased and the settling speed gradually decreased. Therefore, the net increment of water initially increased and then decreased. The total amount of water increased to the maximum and then stabilized. The amount of slurry decreased with the continuous settlement of the tailings. When the pores of the tailings were completely filled with water, the total amount of tailings mortar was constant. Throughout the entire sedimentation process, the trends of both the tailings slurry concentration and the bulk density of the slurry gradually reached their maximums. In the natural settlement procesof tailings, under the combined action of self-gravity and buoyancy of slurry paste, the large particles precipitate in advance, and the small particles settle gradually. With the increasing pressure between settling particles, the pore volume between the tailings graduallydecrease, thus increasing the bulk density of the tailings. In the production process, flocculant is always added to speed up the settling speed of small particles tailings to meet the daily production demand.

3) After evenly mixing the tailings and slag cement with the tailings water, the filling slurries with different mixing ratios were prepared and poured into $70.7 \mathrm{~mm}^{3}$ cube test blocks to 
TABLE 5 | Multiple regression equation for the strength of the filling body at different curing times.

\section{No.}

\section{Regression models}

$\sigma_{03}=13.5672-27.984 \chi_{1}-35.916 \chi_{2}+13.6323 \chi_{1} \chi_{1}+23.9709 \chi_{2} \chi_{2}+36.9638 \chi_{1} \chi_{2}$ $\sigma_{07}=0.55438-36.832 \chi_{1}-1.6721 \chi_{2}+29.2287 \chi_{1} \chi_{1}+1.64595 \chi_{2} \chi_{2}+49.5529 \chi_{1} \chi_{2}$ $\sigma_{28}=4.19585-84.865 \chi_{1}-10.510 \chi_{2}+62.3888 \chi_{1} \chi_{1}+7.83846 \chi_{2} \chi_{2}+112.936 \chi_{1} \chi_{2}$ $\sigma_{60}=36.3514-117.77 \chi_{1}-98.950 \chi_{2}+124.100 \chi^{1} \chi^{1}+70.7577 \chi^{2} \chi^{2}+141.086 \chi^{1} \chi^{2}$

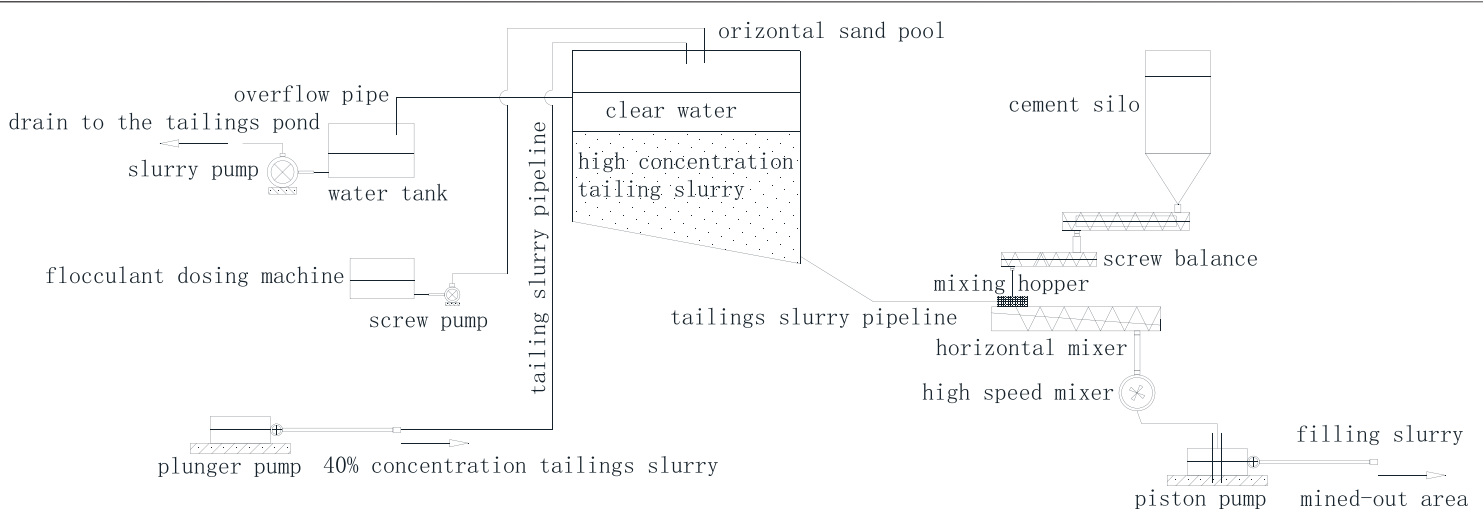

FIGURE 11 | Flow chat of filling process.

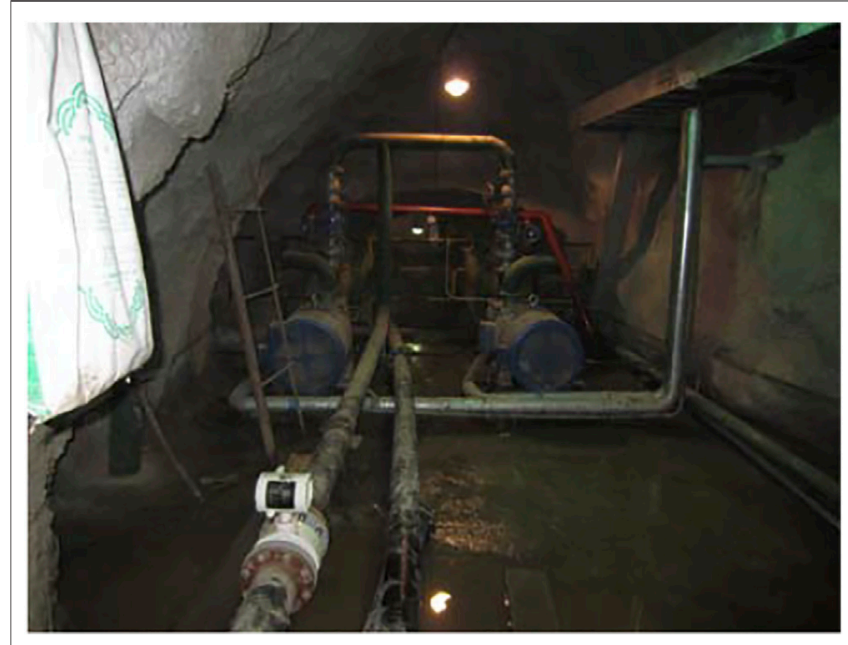

FIGURE 12 | Part of the filling equipment chamber.

test their mechanical properties. For each group of test blocks with different curing times, the test results suggest that as the slag cement content increases and the water content decreases, the uniaxial compressive strength of the filling body increases. The slag cement content plays the dominant role in the strength of the filling body, while the addition of tailings water has little effect on the strength of the filling body. In the statistical analysis of the strength test results of the cemented filling body, the slag cement content (cement-to-tailings ratio)

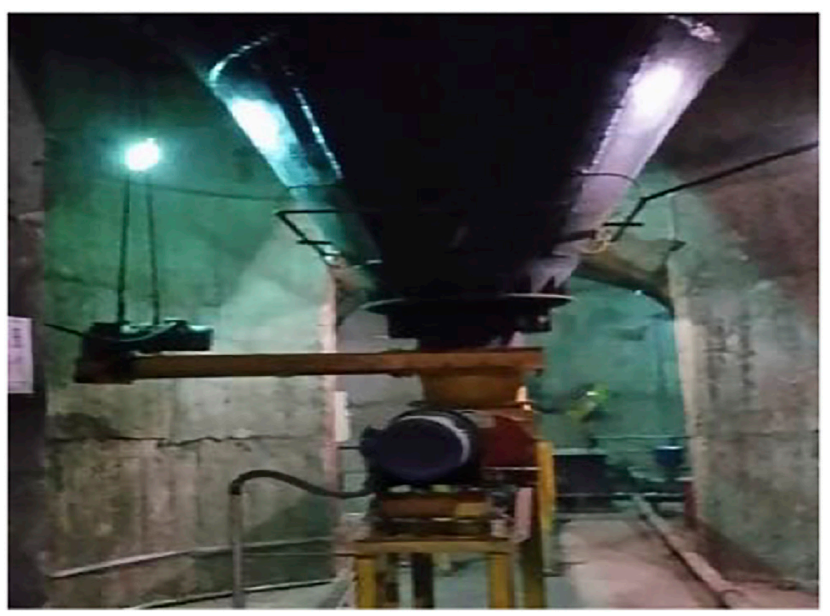

FIGURE 13 | Quantitative feeding of the underground cement silo.

$\chi_{1}$ and the tailings water content (filler slurry concentration) $\chi_{2}$ were taken as two independent variables, and the interaction between the independent variables was taken into account. Multivariate non-linear statistical regression analysis was conducted to obtain the uniaxial compressive strengths of the cemented filling bodies $\sigma_{03}, \sigma_{07}, \sigma_{28}$, and $\sigma_{60}$ at $3,7,28$, and 60 days, respectively.

4) Taken the variation characteristics and influencing factors of backfill strength into account, the value of significance level $a$ 
was set as $0.05 . n-m-1=11-2-1=8$, where $n$ and $m$ were the number of samples tested and the dimension of unknown quantity respectively. As can be seen from the "Correlation coefficient Critical value Table", $R_{0.05}(8)$ is equal to 0.6319 . For the 3, 7, 28 and 60 days strength of the backfill, $R_{03}=0.996592$, $R_{07}=0.995982, R_{28}=0.986532, R_{60}=0.989930$, which are greater than $R_{0.05}(8)$. It indicates that the regression Equations 1 and 2, 3 and 4 are significant at the level of $\alpha=0.05$. That is to say, the cemence-sand ratio and the filling slurry concentration have a significant effect on the strength of the backfill. Through the above correlation coefficient analysis, it can be well explained that the multiple regression model of uniaxial compressive strength at each curing age is of good feasibility, which can provide relevant theoretical basis for the future detection of filling quality.

5) In the daily operation of the filling system, the long-distance pipeline transportation process of the tail mortar was relatively stable, and there was basically no large-scale pipe blockage accident. In the process of pumping and conveying the filling slurry, due to the finer tailings and cement particles, the prepared filling slurry adhered to the inner wall of the pipeline, which reduced the friction of the filling particles with the inner wall of the pipeline and protected the pipeline. During the disassembly inspection of the seamless steel pipes on site, it was found that the filling pipes were less worn. Taking into account the field industrial conditions, the annual ore processing capacity of the Huashugou copper mine is $300,000 \mathrm{t}$ of copper ore, and the annual discharge of the tailings is $277,200 \mathrm{t}$. By adopting the filling method, about $103950 \mathrm{t}$ of copper ore flotation tailings can be continuously filled underground, which can greatly reduce the damage caused to the ecological environment by the tailings discharge, and a large amount of solid waste can be properly treated. After goaf filling, the surrounding broken rock strata can be supported and maintained by high-quality fillings. The fillings can absorb a large amount of the high stress transferred from the strata. Therefore, the movement of the underground strata will decrease and gradually disappear. The collapse and cracking of the surface mountains in the mining area can also be effectively resolved.

6) The goaf filling is adopted to treat the surface collapse in the underground mining in high altitude areas. Although this kind of technology has a broad application prospect, it faces many technical challenges. The climate in high altitude areas is usually harsh, and the low temperature environment in winter is extremely unfavorable to the long-distance pipeline transportation of the filling slurry. Meanwhile, the mineral composition, physical and mechanical property of the filling materials have a great influence on the transportation and mechanical properties of filling materials, which makes the application of filling materials limited. However, all kinds of adverse factors may occur on site, so it is necessary to consider the physical and chemical properties of the filling material, the engineering conditions when select the filling material. The filling material can finally obtain a more reliable promotion value in terms of technology, economy and safety.

\section{CONCLUSIONS}

Limited to the field industrial and engineering conditions, the Huashugou copper mine implemented an underground filling system for goaf filling. Compared with the ground filling station, its design and construction are extremely difficult. This project is typical of similar engineering conditions. It is an underground full tailings-cement cementing filling system, which is rare in China and abroad. The project successfully filled the copper tailings in an underground alpine cold region, and the harmless utilization rate of the tailings filling was about $60 \%$. The remaining $40 \%$ of the tailings were filtered or dry piled, and all of the tailings were treated to achieve harmlessness, thus playing an active role in environmental protection and pollution prevention.

Another difference between the underground filling system and the surface filling station is that because it is deeply buried in a huge mountain, the daily production, construction, and operation spaces are narrow and compact, and the light and ventilation conditions are far poorer than those on the surface. The sensory perspective of the operator is limited. Because these various unfavorable factors will have a series of negative effects on people, the system includes high-efficiency ventilation facilities for pedestrians, lighting, and dust collectors, which improve the quality of the underground working environment and the safety of the operators. Therefore, the construction and completion of the project is innovative.

For the downhole pumping cemented filling system, the safety and reliability of the pump is the key to the smooth operation of the entire system. The particle gradation of the total tailingscement mixture slurry of the Huashugou copper mine is relatively reasonable, and the formed slurry does not have obvious segregation, which is convenient for pipeline pumping and conveying. After the filling slurry enters the goaf, it can basically be consolidated and hardened within $24-36 \mathrm{~h}$, and the resulting filling body has uniform and reliable mechanical properties, which meet the double-layer technical requirements of large-scale copper deposit mining and bulk mine industrial solid waste disposal.

\section{DATA AVAILABILITY STATEMENT}

The original contributions presented in the study are included in the article/Supplementary Material, further inquiries can be directed to the corresponding authors.

\section{AUTHOR CONTRIBUTIONS}

DD wrote the main text of the manuscript. GC and YL collected and analyzed the data. All authors reviewed and commented on the manuscript. 


\section{FUNDING}

The authors gratefully acknowledge support for this research from the National Natural Science Foundation of China (51764009), and the Guizhou Province Science

\section{REFERENCES}

Behera, S. K., Mishra, D. P., Ghosh, C. N., Mandal, P. K., Singh, K. M. P., Buragohain, J., et al. Characterization of lead-zinc Mill Tailings, Fly Ash and Their Mixtures for Paste Backfilling in Underground Metalliferous Mines. 2019, 78(14):1-13. doi:10.1007/s12665-019-8395-9

Belem, T., Benzaazoua, M., and Bussière, B., 2000. Mechanical Behaviour of Cemented Paste Backfill. In: Proc. of 53rd Candadian Geotechnical Conference, Montrea, Canada, October 2000, pp. 373-380.

Belem, T., Bussière, B., and Benzaazoua, M. (2001). "The Effect of Microstructural Evolution on the Physical Properties of Paste Backfill," in Proc. Of Tailings and Mine Waste'01 Janvier, 2001, Fort Collins, Colorado, USA, 16-19 January 2001, 365-374.

Benzaazoua, M., Fall, M., and Belem, T. (2004). A Contribution to Understanding the Hardening Process of Cemented Pastefill. Minerals Eng. 17 (2), 141-152. doi:10.1016/j.mineng.2003.10.022

Benzaazoua, M., Ouellet, J., Servant, S., Newman, P., and Verburg, R. (1999). Cementitious Backfill with High Sulfur Content Physical, Chemical, and Mineralogical Characterization. Cement Concrete Res. 29, 719-725. doi:10.1016/s0008-8846(99)00023-x

Bruno, B., Bruno, B., Yilmaz, E., Benzaazoua, M., and Belem, T., (2010). Assessment of the Modified CUAPS Apparatus to Estimate In Situ Properties of Cemented Paste Backfill. Geotechnical Test. J. 33(5). doi:10.1520/GTJ102689

Cai, M., and Brown, E. T. (2017). Challenges in the Mining and Utilization of Deep Mineral Resources. Engineering 3 (4), 432-433. doi:10.1016/ j.eng.2017.04.027

chao, X. Y., Xu, T., Wasantha, P. L. P., Yang, T. H., and Fu, T. F. (2020). Dynamic Disaster Control of Backfill Mining under Thick Magmatic Rock in One Side Goaf. A case study 27 (10), 3103-3117. doi:10.1007/s11771-020-4532-6

Chen, S., Du, Z., Zhang, Z., Yin, D., Feng, F., and Ma, J. (2020). Effects of Red Mud Additions on Gangue-Cemented Paste Backfill Properties. Powder Tech. 367, 833-840. doi:10.1016/j.powtec.2020.03.055

Cui, L. (2018). Mamadou Fall. Multiphysics Modeling and Simulation of Strength Development and Distribution in Cemented Tailings. Backfill Structures 12 (1), 1-22. doi:10.1186/s40069-018-0250-y

de Souza, A., Manoel dos Santos, C., Ihaddadene, R., Cavazzana, G., Abreu, M. C., Pobocikova, I., et al. (2021). Analysis of Extreme Monthly and Annual Air Temperatures Variability Using Regression Model in Mato Grosso Do Sul, Brazil. Model. Earth Syst. Environ. 2021, 1-17. doi:10.1007/s40808021-01096-6

Deng, X., Zhang, J., Zhou, N., An, T., and Guo, S., (2014). The Research and Application of Longwall-Roadway Cemented Backfilling Mining Technology in Extra-thick Coal Seam. J. Mining Saf. Eng. 31(06):857-862. doi:10.1007/s12665017-7120-9

Emad, M. Z., Mitri, H., and Kelly, C. (2018). Dynamic Model Validation Using Blast Vibration Monitoring in Mine Backfill. Int. J. Rock Mech. Mining Sci. 107, 48-54. doi:10.1016/j.ijrmms.2018.04.047

Emad, M. Z., Mitri, H., and Kelly, C. (2015). In-situ Blast Vibration Monitoring in Cemented Rockfill Stope - a Case Study. Int. J. Mining, Reclamation Environ. 31 (2), 119-136. doi:10.1080/17480930.2015.1123600

Emad, M. Z., Mitri, H. S., and Henning, J. G. (2012). Effect of Blast Vibrations on the Stability of Cemented Rockfill. Int. J. Mining, Reclamation Environ. 26 (3), 233-243. doi:10.1080/17480930.2012.707527

Fang, K., and Mamadou, F. (2020). Insight into the Mode I and Mode II Fracture Toughness of the Cemented Backfill-Rock Interface: Effect of Time, Temperature and Sulphate. Construction Building Mater. 262, 120860. doi:10.1016/j.conbuildmat.2020.120860 and Technology Support Plan Project [Grant No. (2018) 2836], and the Scientific Research Fund of Hunan Province Education Department (20A475), and the Highlevel Talent Gathering Project in Hunan Province (2019RS1059).

Freise, F., Gaffke, N., and Schwabe, R., (2021). Convergence of Least Squares Estimators in the Adaptive Wynn Algorithm for Some Classes of Nonlinear Regression Models. Metrika. 84(6)1-24. doi:10.1007/s00184-020-00803-0

Khoshand, A., and Fall, M. (2016), Geotechnical Characterization of Peat-Based Landfill Cover Materials.J. Rock Mech. Geotechnical Eng.,8(05):596-604. doi:10.1016/j.jrmge.2016.05.007

Li, B., Zhou, N., Qi, W., Li, A., and Cui, Z. (2020). Surface Subsidence Control during Deep Backfill Coal Mining: A Case Study. Adv. Civil Eng. 2020, 1-12. doi:10.1155/2020/6876453

Li, L., and Aubertin, M. (2012). A Modified Solution to Assess the Required Strength of Exposed Backfill in Mine Stopes. Can. Geotech. J. 49 (8), 994-1002. doi:10.1139/t2012-056

Liang, P., Ran, W., Ying, X., and Yao, Z., (2013) Experimental Study on Flocculant Selection for Tailings Settlement.Mining Tech. 13(6),47-49. doi:10.3969/ j.issn.1671-2900.2013.06.019

Lu, G., and Fall, M. (2018). Modeling Postblasting Stress and Pore Pressure Distribution in Hydrating Fill Mass at an Early Age. Int. J. Geomechanics, 18(8). doi:10.1061/(asce)gm.1943-5622.0001141

Na, H., Lv, G., Wang, L., Liao, L., Zhang, D., Guo, L., et al. (2021). A New Expansion Material Used for Roof-Contacted Filling Based on Smelting Slag. Sci. Rep. 11 (1), 2607. doi:10.1038/s41598-021-81891-4

Oleg, B., Mykhailo, P., Vasyl, L., Serhii, Z., Sai, K., Saik, P., et al. (2021). Sustainable Underground Iron Ore Mining in Ukraine with Backfilling Worked-Out Area, Sustainability, 13(2):834. doi:10.3390/su13020834

Ouattara, D., Mbonimpa, M., Yahia, A., and Belem, T. (2018). Assessment of Rheological Parameters of High Density Cemented Paste Backfill Mixtures Incorporating Superplasticizers. Construction Building Mater. 190, 294-307. doi:10.1016/j.conbuildmat.2018.09.066

Qiao, D., Cheng, W., Xie, J., Wang, J., Huang, F., Mo, Y., et al. (2019). Analysis of the Influence of Gradation on the Strength of a Cemented Filling Body and the Cementation Strength Model. Integrated Ferroelectrics 199 (1), 12-21. doi:10.1080/10584587.2019.1592593

Quan, f. Y., He, J., and Wang, Z. (2007). Application of Multiple Linear Regression in Ore Body Mining. J. Xi'an Univ. Sci. Technol. (04), 555-558. doi:10.3969/ j.issn.1672-9315.2007.04.004

Ran, W., Kang, R., and Liang, P. (2014). Experimental Study on Adding Amount of Flocculant. Mining Tech. 14 (4), 52-53. 81. doi:10.3969/j.issn.16712900.2014.04.021

Sun, Y. X., and Ren, D. W., (2012). Preparation System Design of Filling Material with Coal Gangue as Coarse Aggregate, 1480:135-138. doi:10.4028/ www.scientific.net/AMR.361-363.135

Tan, Y.-y., Yu, X., Elmo, D., Xu, L.-h., and Song, W.-d Experimental Study on Dynamic Mechanical Property of Cemented Tailings Backfill under SHPB Impact Loading.Int. J. Minerals Metall. Mater., 2019, 26(04): 404-416. doi:10.1007/s12613-019-1749-1

Wang, J., (2013). Study on the Properties of Cemented Filling Material of Whole Tailings in Huashugou Copper Mine, Jingtieshan Mine.Sci. Tech. Info. 46 (12),90-91. doi:10.3969/j.issn.1672-3791.2013.12.054

Wen bin, X., Liu, B., and Wu, W. 1., (2021). Strength and Deformation Behaviors of Cemented Tailings Backfill under Triaxial Compression. J. Cent. South Univ., 27(12), 3531-3543. doi:10.1007/s11771-020-4568-7

Wu, J., Yin, Q., and Gao, Y., (2021). Particle Size Distribution of Aggregates Effects on Mesoscopic Structural Evolution of Cemented Waste Rock Backfill. Environ. Sci. Pollut. Res. 28, (2):1-13. doi:10.1007/s11356-02011779-9

Xu, W., Tian, X., Qiu, Y., Dang, P., and Yin, T., (2017). Experiment of the Resistivity Characteristic of Cemented Backfill Mass during the Whole Consolidation Process.J. China Univ. Mining Tech. 46(02):265-272+344. doi:10.13247/j.cnki.jcumt.000648 
Zaka, E. M., and MitriHani, K. C., (2014). Effect of Blast-Induced Vibrations on Fill Failure in Vertical Block Mining with Delayed Backfill. Can. Geotechnical J. 51(9):975-983. doi:10.1139/cgj-20130305

Zhang, S., Yang, L., and Qiu, J. (2021). Fluidity and Strength Behaviors of Cemented Foam Backfill: Effect of Particle Size Distribution and Foaming Agent Dosage.Bull. Eng. Geology. Environ. 80(4):3177-3191. doi:10.1007/ s10064-021-02117-5

Zhang, X., Xu, M., Liu, L., Huan, C., Zhao, Y., Qi, C., et al. (2020). Experimental Study on thermal and Mechanical Properties of Cemented Paste Backfill with Phase Change Material. J. Mater. Res. Tech. 9 (2), 2164-2175. doi:10.1016/ j.jmrt.2019.12.047

Zhao, K., Xiang, Y., and Zhu, S. (2020). Acoustic Emission Investigation of Cemented Paste Backfill Prepared with Tantalum-Niobium Tailings. Construction Building Mater. 237, 117523. doi:10.1016/ j.conbuildmat.2019.117523

Zheng, J., and Li, L. (2020). Experimental Study of the "Short-Term" Pressures of Uncemented Paste Backfill with Different Solid Contents for Barricade Design. J. Clean. Prod. 275 (1), 123068. doi:10.1016/ j.jclepro. 2020.123068

Conflict of Interest: The authors declare that the research was conducted in the absence of any commercial or financial relationships that could be construed as a potential conflict of interest.

Publisher's Note: All claims expressed in this article are solely those of the authors and do not necessarily represent those of their affiliated organizations, or those of the publisher, the editors and the reviewers. Any product that may be evaluated in this article, or claim that may be made by its manufacturer, is not guaranteed or endorsed by the publisher.

Copyright (C) 2021 Deng, Cao and Liang. This is an open-access article distributed under the terms of the Creative Commons Attribution License (CC BY). The use, distribution or reproduction in other forums is permitted, provided the original author(s) and the copyright owner(s) are credited and that the original publication in this journal is cited, in accordance with accepted academic practice. No use distribution or reproduction is permitted which does not comply with these terms. 